\title{
Diagnostic Quality
}

National Cancer Institute

\section{Source}

National Cancer Institute. Diagnostic Quality. NCI Thesaurus. Code C84423.

Indicates a biomedical image that is of acceptable quality, with no technical defect likely to impair using the image for diagnosis. 